\title{
Development of Eco-Friendly Deconstruction Technologies for Recycling Construction Waste
}

\author{
Myungkwan Lim ${ }^{1,2}$, Heesup Choi ${ }^{1,2 *}$, Hyeonggil Choi ${ }^{3}$, Ryoma Kitagaki ${ }^{3}$, \\ Takahumi Noguchi ${ }^{3}$ \\ ${ }^{1}$ Department of Archtecture Engineering, Hankyong National University, Gyeonggi-do, Korea \\ ${ }^{2}$ Department of Civil Engineering, Kitami Institute of Technology, Hokkaido, Japan \\ ${ }^{3}$ Department of Architecture, The University of Tokyo, Tokyo, Japan \\ Email: ${ }^{*}$ choiheesup@gmail.com
}

Received 25 March 2014; revised 25 April 2014; accepted 19 May 2014

Copyright (C) 2014 by authors and Scientific Research Publishing Inc.

This work is licensed under the Creative Commons Attribution International License (CC BY). http://creativecommons.org/licenses/by/4.0/

c) (i) Open Access

\section{Abstract}

Recently, the intended use and required performance of buildings are rapidly changing with advances in scientific technology and globalization. Furthermore, given the population growth in semi-developed and developing countries, economic growth, increasing waste, and increasing amounts of energy consumption, the industry requires the development of efficient methods to deconstruct old buildings by reducing waste and saving as much energy as possible during periods of urban redevelopment and maintenance. In general, either an ordinary breaker or a hydraulic breaker is used to deconstruct reinforced concrete buildings. This deconstruction method has the ability to shorten the construction period compared to the other methods, but it is difficult to separate the debris that gets mixed when the deconstruction is completed, as it is a rough construction method that uses large equipment. This study develops a technology that can be used to selectively heat, separate, and deconstruct the steel reinforcement inside reinforced concrete, treating the reinforcement as a conductive resistor and applying high-frequency induction heating to the reinforced concrete structure. Specifically, this study verifies the temperature characteristics of deformed bars inside reinforced concrete, the occurrence of cracks due to thermal fracture of the deformed bars, and chemical and physical weakening of concrete by thermal conduction on the surface of steel reinforcement using the high-frequency induction heating technology. Furthermore, this study considers the extent of concrete weakening in the heating range of appropriate energy and carries out a technical review of the stages that would be actually applied. This technology involves low noise and low pollution levels, and it increases the collection rate of steel reinforcement inside separated reinforced concrete members and the recycling rate of construction wastes; thus,

\footnotetext{
"Corresponding author.
} 
its use is expected to reduce the energy consumption by minimizing secondary processing. Keywords

Recycling, Deconstruction, Heat Induction, Ease to Scrap, Weakening

\section{Introduction}

Despite the annually increasing number of buildings, there is little literature on deconstruction methods. Deconstruction is strictly constrained by the surrounding environments, especially in downtown areas, and environmental pollution and safety issues such as the noise, vibration, and dust that occur during the deconstruction process also cause problems [1] [2]. The existing deconstruction methods rely largely on labor owing to the lack of deconstruction technology and experience, which causes waste of labor and loss of available materials as well as extended construction period [3]. The existing deconstruction methods do not consider the recycling of debris that occurs during the deconstruction process [4]. The reason why the actual recycling rate is problematic despite continuous recycling of wasted concrete lies in the existing deconstruction methods [5], in which various problems related to the reuse and recycling of wastes that occur owing to indiscriminate deconstruction have been pointed out [6] [7]. In the case of a hydraulic breaker or large breaker, the representative method for the current separating dismantlement, it is necessary to separate concrete members and waste. In particular, in the case of reinforced concrete members dismantled using heavy equipment, various problems can occur with regard to the reuse of steel reinforcement and recycling of waste concrete [8].

- It is necessary to convert the current "first dismantle and then separate" method to a "separate first and then dismantle" method and develop technology to improve the recycling rate that considers the efficient collect of demolished debris in the dismantlement stage.

- It is necessary to develop a partial-dismantlement technology that is effective for remodeling and repair reinforcement. Partial dismantlement, which is on the rise with the increase in remodeling and repair reinforcement, requires various technical applications and developments that are different from the existing dismantlement in terms of prevention of damage to the remaining structure or improvement in safety.

- It is necessary to propose a comprehensive management system that systemizes separating dismantlement and partial dismantlement to promote the development of the current dismantlement industry and of the entire architectural industry. This secures safety in dismantling construction, reduction in environment-polluting factors, proper handling of generated waste, and improvement in the recycling rate.

\section{Complete Deconstruction Technology for Reinforced Concrete Members Using High-Frequency Induction Heating Method}

\subsection{Steel Reinforcement Heating Mechanism Depending on High-Frequency Induction Heating (Joule Heat)}

Induction heating is a method that is used to heat conductive resistors such as metals by electrical energy that is converted from a high-frequency current-carrying conductor known as an induction coil. If alternating current flows in the lead wire, a line of magnetic force with changing direction and intensity in the surroundings occurs. If conductive materials (usually metal) are placed in the surroundings, as shown in Figure 1, an eddy current flows inside the metal, influenced by this changing line of magnetic force. As metal usually has an electrical resistance, Joule heating [electricity $=$ current $^{2}$ ] occurs, and the metal is heated if the current flows in the metal. This phenomenon is called induction heating. Induction heating is less likely to be a risk, and the heat loss is also less, although the temperature rises in the non-heated areas, because only the metal is heated [9] [10].

\subsection{Skin Effect and Depth of Penetration $\delta$}

In general, most currents are concentrated on the surface of a conductive resistor because the current density drops at the center of the conductive resistor if alternating current flows through it. This phenomenon is called the skin effect. When it gets closer to the center of the conductive resistor, the cross velocity of the magnetic 


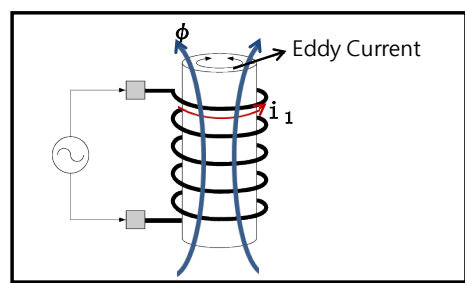

(a)

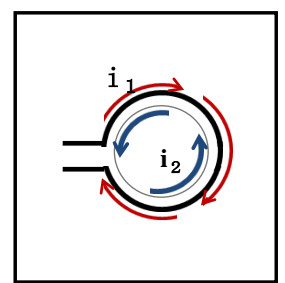

(b)

Figure 1. High-frequency induction heating mechanism. (a) Magnetic flux $\boldsymbol{\varphi}$ depending on alternating current $\mathbf{i}_{1}$; (b) Induced current (Eddy Current $\mathbf{i}_{2}$ ).

field speeds up. It can also be caused by the difficult flow of alternating current when the inductance increases. In Equation (1), $\delta[\mathrm{mm}]$, the penetration depth of a high-frequency current is determined by the material permeability $\mu[\mathrm{H} / \mathrm{m}]$, the conductivity of the heated object $\sigma[\mho / \mathrm{m}]$, and the frequency $\mathcal{f}[\mathrm{Hz}]$.

$$
\delta=\frac{1}{\sqrt{\pi f \mu \sigma}}
$$

Equation (1) shows the penetration depth increases when the frequency decreases or when the material permeability and conductivity of the heated object decrease. As $90 \%$ of heating occurs from the surface to $\delta$ in terms of current and power distribution, it can be said that all eddy currents are concentrated to the depth of penetration $\delta$ from the surface of a conductive resistor [11] [12].

\subsection{Thermal Model of Steel Reinforcement Using High-Frequency Induction Heating}

If high-frequency alternating-current flows into the coil, an eddy current is induced and acts as source of heat that depends on the resistance of metal; here, resistance causes heat in the metal. In the case of high-frequency induction heating, there is a large difference in heating efficiency depending on the magnetic characteristics of the heated object, but a larger eddy current is induced with a magnetic substance, which is significantly affected by the magnetic field, depending on the changes in time [13].

As shown in Equation (2), the hysteresis constant $\eta$ varies depending on the magnetic quality of a material; unlike the general transformer, it is easy to heat material with larger $\eta$ in induction heating. However, as the heated objects are not usually made in a closed circuit like a transformer, the density of the magnetic field velocity and the effective permeability are small and $\eta$ is also small, even if the heated object is a magnetic substance like cast iron. In addition, if the frequency is over about $10[\mathrm{kHz}]$, the hysteresis loss depending on the induction heating can be neglected because the eddy current loss is overwhelmingly greater than the square of frequency (as shown in Figure 2).

In the case of a magnetic substance, the efficiency of the heating surface increases because the depth of penetration decreases with increasing relative permeability. For steel reinforcement, with a relatively high permeability, localized heating on the surface is possible because the induced current is concentrated on the areas facing the heating coil when the magnetic field occurred from the coil is absorbed into the surface of the metal. In addition, selectively localized heating is possible because the scope of the magnetic field can be adjusted according to the diameter of the heating coil. Figure 3 represents the heating model of steel reinforcement, which depends on the high-frequency induction heating [13] [14].

$$
\mathrm{P}_{h}=\eta f\left(\mathrm{~B}_{m}\right)^{2} \mathrm{~V}
$$

$\eta$ : hysteresis constant.

$V$ : central volume of steel reinforcement $\left(\mathrm{m}^{3}\right)$.

The principle of the magnetic field generated by the coil is summarized in accordance with Maxwell's equations. As shown in Figure 3, coils are distributed within a particular space; if current $i(t)$ is flowing, the magnetic vector potential A occurs at any point within the space $P(x, y, z)$. Equation (3) is the interaction formula for both the current density $J$ and the magnetic vector potential $A$.

$$
A=\frac{\mu}{4 \pi} \int_{V} \frac{J}{\gamma} d V
$$




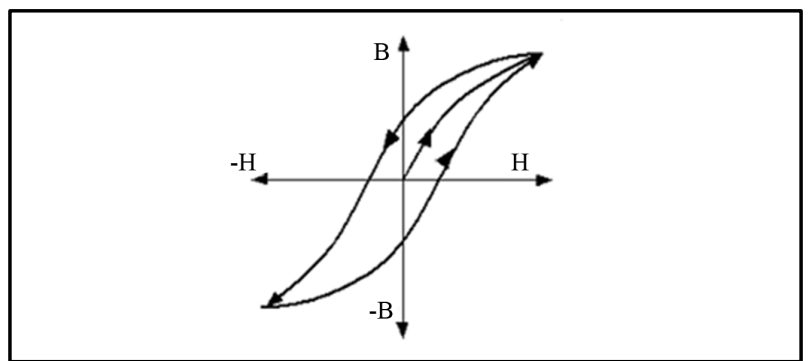

Figure 2. Hysteresis loop [15].

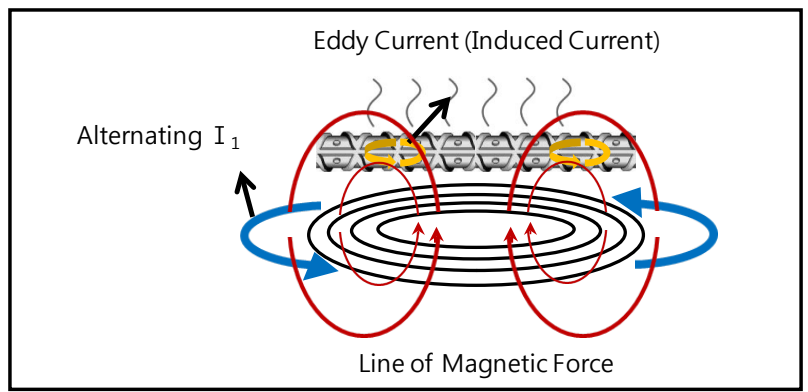

Figure 3. Thermal Model of Steel Reinforcement Depending on High-Frequency Induction Heating.

If current is alternating, the magnetic vector potential $A$ is also alternating. Equation (4) is the relationship between the magnetic vector potential and the magnetic flux density (magnetic field velocity) $B$.

$$
B=\nabla \times A
$$

If the magnetic vector potential $A$ is alternating, the magnetic flux density $B$ is also alternating. Therefore, if a conductive resistor is used, power failure $E$ occurs depending on Equation (5). From this current, an eddy current $J$ occurs.

$$
\begin{gathered}
\nabla \times E=-\frac{\partial B}{\partial t} \\
J=\sigma E
\end{gathered}
$$

$\sigma$ : conductivity of a conductive resistor.

The entire magnetic field is determined mutually by the magnetic field due to the current that flows in the coil and the magnetic field due to the Foucault current. This causes an electromotive force in the coil. As shown in Equation (7), the electromotive force in the coil is the electric field that occurs when heating the coil.

$$
V=\oint_{\mathrm{C}} \mathrm{E} \cdot d \ell=\oint_{\mathrm{C}}\left(-\frac{\partial \mathrm{A}}{\partial \mathrm{t}}\right) d \ell
$$

Therefore, a magnetic field in the center of the steel reinforcement, a conductive resistor, occurs that depends on the distribution of the eddy current, if coils are distributed closely to the steel reinforcement [15].

\section{Temperature Characteristics of Single Steel Reinforcement Depending on High-Frequency Induction Heating}

\subsection{Experimental Overview}

This study carries out an experiment to analyze the temperature characteristics of a deformed bar, commonly used as a conductive resistor in high-frequency induction heating, and the temperature distribution of steel reinforcement accordingly. This study sets the conditions for the diameter and length of steel reinforcement, especially of the deformed bar widely used in the field, the temperature rise characteristics and temperature distribution depending on the distance from the heating coil to the surface of steel reinforcement, and the 
quantity of output as experimental factors. This study identifies the temperature rise characteristics and temperature distribution at various conditions because there are large differences in heating efficiency depending on the differences in heat transfer coefficients by cross-sectional area and distance of steel reinforcement within the range of the magnetic field in high-frequency induction heating. In addition, the main purpose is to predict the temperature characteristics as basic information for various arrangements of steel reinforcement. Furthermore, this study determines the optimal conditions for output and heating positions because the depth of penetration varies with the frequency.

\subsection{Experimental Method}

\subsubsection{Induction Heating Device}

For induction heating, this study uses an experimental device with a basic frequency of $120 \mathrm{kHz}$ (operating frequency of $60-120 \mathrm{kHz}$ ) and a maximum high-frequency output of $6 \mathrm{~kW}$. The output stability is $\pm 2 \%$, and the output can be adjusted depending on the DC voltage [16]. High-frequency induction heating is a characteristic of the changed operating frequency when changing the coils, because the heating coil and heated object become one component of the circuit, and the high-frequency power is set by a resonant condenser inside the matching circuit, output lead, inductance, and inductance of heating coil. Resonant frequency employs an automatic tracking method. The heating coil is a fan-cake type and uses a coil with dimension of $\varphi 120$, rev count of 3 , and coil thickness of $\varphi 10$.

\subsubsection{Steel Reinforcement Heating Experiment}

For the single steel reinforcement heating experiment, this study uses $150-\mathrm{mm}$ steel reinforcement samples of D6, D10, D19, D25, and D32 in SD345 to identify the temperature distribution of steel reinforcement depending on the optimum output and heating. The maximum output is either $5 \mathrm{~kW}$ or $6 \mathrm{~kW}$, and the experiment is carried out by changing the distance from the surface of the steel reinforcement to the lower bottom of the induction heating coil and measuring the temperature at the central point on the surface of steel reinforcement.

To form an arrangement similar to that of reinforced concrete specimens, this study carries out an experiment by cutting every steel reinforcement sample to $430 \mathrm{~mm}$. This study measures the temperature at three positions using a heat-resistant camera: at the center of the surface of steel reinforcement, at the part facing the coil diameter, and at the part $30 \mathrm{~cm}$ away from the coil diameter. The heating experiment method for single steel reinforcement is show in Figure 4.

\subsection{Temperature Rise Characteristics of Single Steel Reinforcement Depending on High-Frequency Induction Heating}

The temperature rise characteristics of steel reinforcement with induction heating (length: $150 \mathrm{~mm}$ ) are presented in Figure 5 for output powers of $5 \mathrm{~kW}$ and $6 \mathrm{~kW}$. As temperatures of $800^{\circ} \mathrm{C}$ or above are difficult to measure, any temperature above this mark is regarded as "being at $800^{\circ} \mathrm{C}$ ". There are no large differences between $5 \mathrm{~kW}$ and $6 \mathrm{~kW}$. Over a certain output, the depth of penetration with induction heating increases depending on the quantity of output, but if the temperature is over the Curie temperature at the surface of the steel reinforcement, the relative permeability falls to 1 [17]. The output of the electric field drops and loss occurs because the electric field reaches the critical temperature, even in the inside, without being further increased.

In the relationship between time and temperature, the targeted temperature (concrete-weakening temperature) reached up to $300^{\circ} \mathrm{C}$ within 60 seconds when the distance from the heating coil to the surface of steel reinforcement was $10 \mathrm{~mm}, 20 \mathrm{~mm}$, or $30 \mathrm{~mm}$. As the distance decreased, the temperature rose rapidly, to $600^{\circ} \mathrm{C}$ or above. In addition, at distances of $10 \mathrm{~mm}$ or $20 \mathrm{~mm}$, there is a thermal equilibrium between $600^{\circ} \mathrm{C}-800^{\circ} \mathrm{C}$, and at a distance of $30 \mathrm{~mm}$, there is a thermal equilibrium between $500^{\circ} \mathrm{C}-700^{\circ} \mathrm{C}$. At $50 \mathrm{~mm}$, the temperature reduces to $300^{\circ} \mathrm{C}$ in about $300 \mathrm{~s}$.

D6, D10, D19, and D25 showed a rapid temperature rise characteristic, but D32 showed reduced temperature rise trend compared to the other types of steel reinforcement. This may occur because as the induction heating heats the surface of steel reinforcement rapidly, the steel reinforcement with a thick diameter requires time to obtain a temperature difference by heating until the molecular motion can become constant depending on the heat within the steel reinforcement.

The results of heating the 430-mm-long steel reinforcement using the high-frequency induction heating 


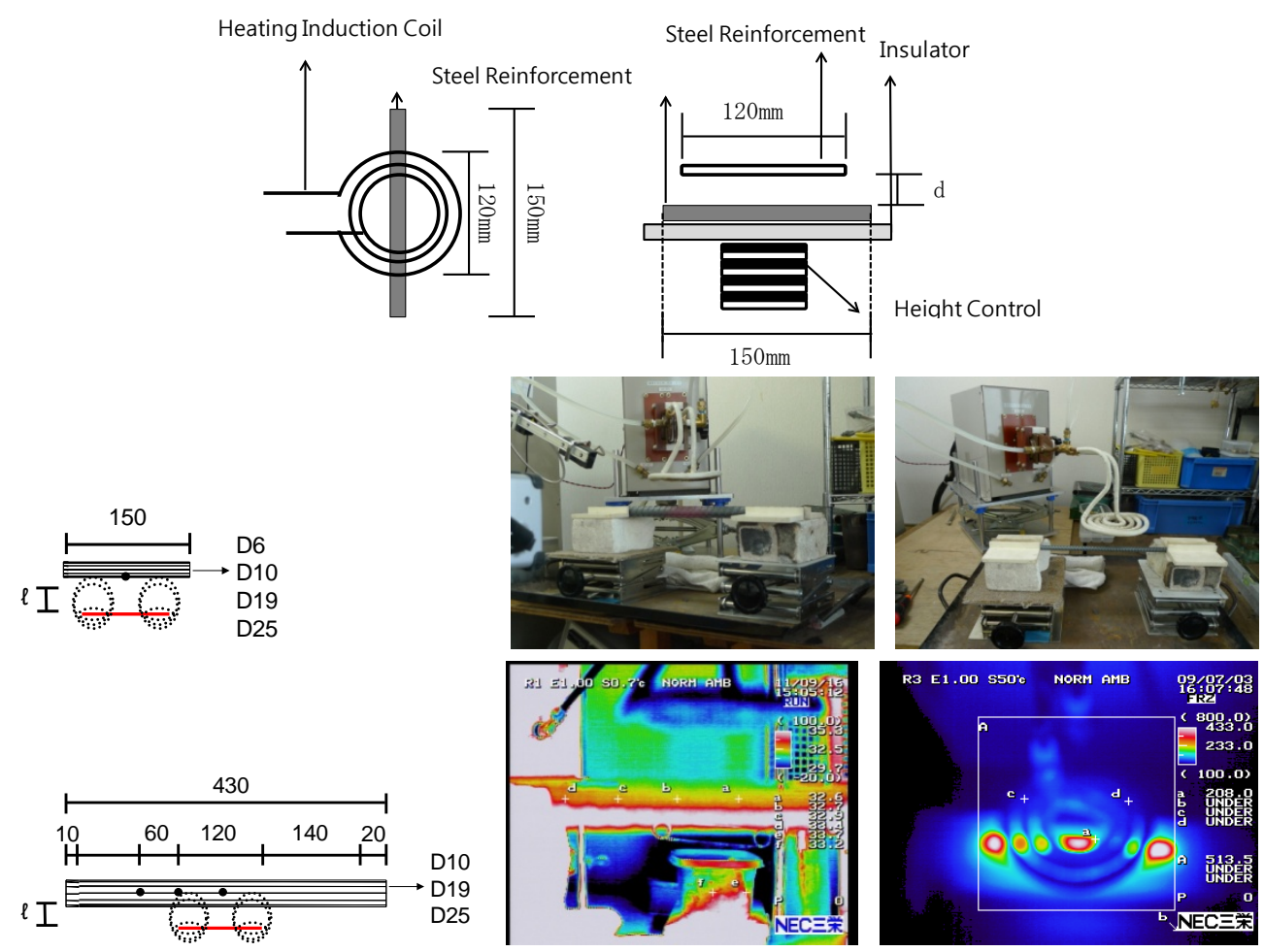

Figure 4. Experimental method of single steel reinforcement heating using high-frequency induction heating method.

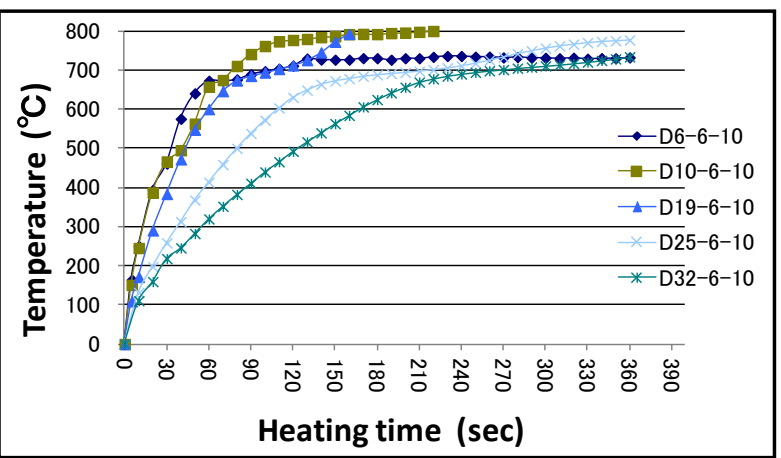

(a)

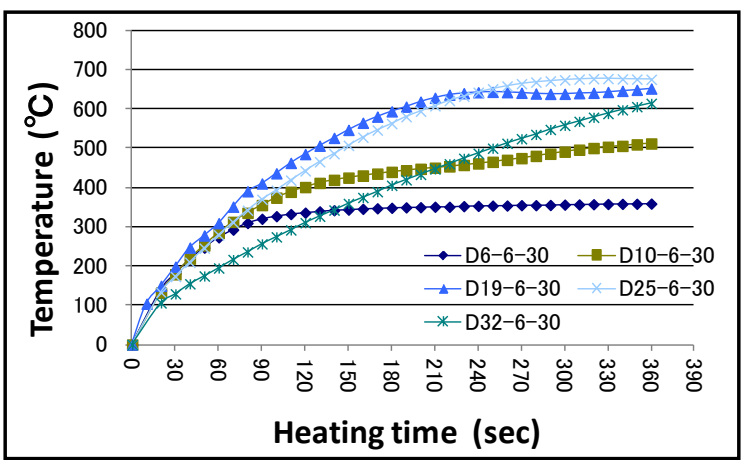

(b)

Figure 5. Temperature rise characteristics of steel reinforcement depending on high-frequency induction heating (measured at $150 \mathrm{~mm}$-center). (a) $5 \mathrm{~kW}-10 \mathrm{~mm}$; (b) $6 \mathrm{~kW}-30 \mathrm{~mm}$. Note: D00-0-0: D (reinforced type)-output (kW)-heating distance $(\mathrm{mm})$.

method are shown in Figure 6. Heating with an output of $5 \mathrm{~kW}$ showed temperature rise characteristics similar to that of the 150-mm-long steel reinforcement. This may be because little heat conduction loss occurs depending on the length of steel reinforcement and because selective heating is possible depending on the heating location.

\subsection{Temperature Distribution Characteristics of Single Steel Reinforcement Depending on High-Frequency Induction Heating}

The steel reinforcement heating process using the induction heater can be problematic owing to unnecessary heating, lack of heating, and concrete weakening depending on the temperature rise. This study analyzes the temperature distribution of steel reinforcement at the induction heating conditions of $5 \mathrm{~kW}$ and $6 \mathrm{~kW}$ using infrared radiation temperature measurement at $10 \mathrm{~mm}$, where the highest temperature rise occurred; the results 


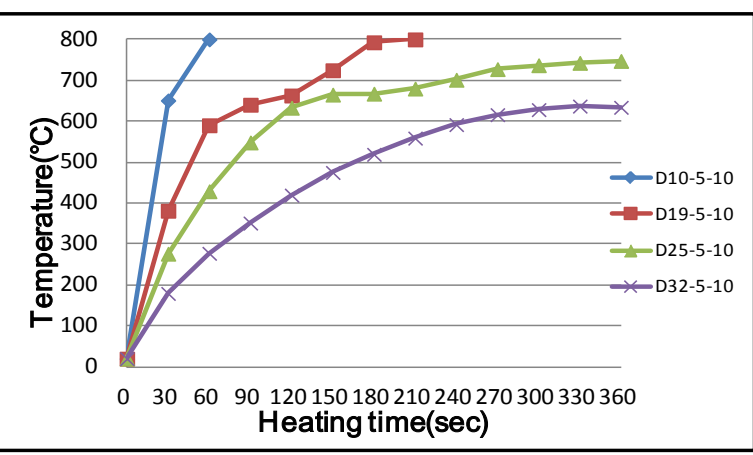

(a)

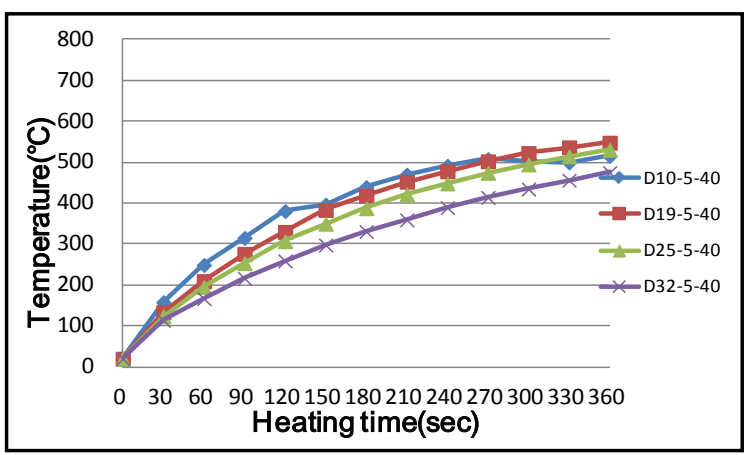

(b)

Figure 6. Temperature rise characteristics of steel reinforcement depending on high frequency induction heating (measured at $450 \mathrm{~mm}$-center). (a) $5 \mathrm{~kW}-10 \mathrm{~mm}$; (b) $5 \mathrm{~kW}-30 \mathrm{~mm}$.

are shown in Figure 7. The horizontal axis of the figure is $150 \mathrm{~mm}$, i.e., the length of the specimen, but there are some errors in the range of temperatures owing to the radiant heat when measuring using the infrared ray temperature. The horizontal axis is $160 \pm 5 \mathrm{~mm}$ on average, and the error of $10 \pm 5 \mathrm{~mm}$ due to radiant heat does not have a large effect on the heating phenomenon at the center or at the end. Most of the specimens demonstrated that heating was more concentrated at the central part compared to at the end. The 120-mm-diameter steel reinforcement that was out of the heating coil showed a difference of $150^{\circ} \mathrm{C}-450^{\circ} \mathrm{C}$ compared to the central part.

As the diameter of the heating coil was $120 \mathrm{~mm}$ in the experiment wherein the $430-\mathrm{mm}$ steel reinforcement is heated at $5 \mathrm{~kW}$, the point was measured with a distance of $30 \mathrm{~mm}$ from the center of the coil diameter toward the longitudinal direction of the steel reinforcement; the result is shown in Figure 8. There was not a large difference in temperature within the coil diameter, but the inside of the coil showed a temperature difference of $100^{\circ} \mathrm{C}$ or more when the external coil diameter was $30 \mathrm{~mm}$ or above. Most of the steel reinforcement showed a temperature rise by thermal conductivity of steel reinforcement outside of the magnetic field with an external coil diameter of $60 \mathrm{~mm}$ or above, which suggested that this was a localized heating phenomenon.

A high-temperature phenomenon on the surface of the steel reinforcement was identified at $400^{\circ} \mathrm{C}-500^{\circ} \mathrm{C}$ in many cases. This high-temperature phenomenon was found only inside the heating coil, and the high-temperature phenomenon due to thermal conduction did not appear, which suggested that there was a localized heating phenomenon due to selective heating.

\section{Temperature Characteristics of Cross-Steel Reinforcement Depending on High-Frequency Induction Heating}

\subsection{Experimental Overview}

This study carries out an experiment to analyze the temperature rise characteristics and temperature distribution depending on high-frequency induction heating using SD345 steel reinforcement. This study identifies the temperature rise characteristics that can be found when using the single steel reinforcement and the changes in temperature distribution with cross-arrangement similar to that in an actual structure. If the steel reinforcement crosses, there may be a difference in heat characteristics caused by heating and conduction caused by resistance depending on the characteristics of the magnetic field. In addition, as the surface facing the coil increases and there is a large difference in heat transfer rate depending on the distance from the major steel reinforcement arranged at the bottom and the resistance area, it is expected that there will be a difference in temperature rising slope and the positioning of the heating coil.

This study identifies temperature rise characteristics, temperature gradient, and temperature distribution depending on the arrangement of steel reinforcement and distance heating calculated by thickness of covering.

\subsection{Experimental Method}

To identify the appropriate quantity of output or temperature distribution of steel reinforcement in the cross-steel reinforcement heating experiment, this study uses steel reinforcement of D10, D19, D25, and D32 in the case of 


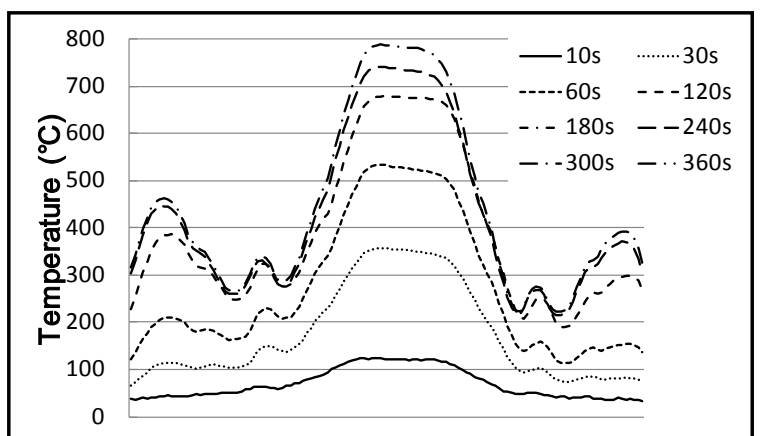

(a)

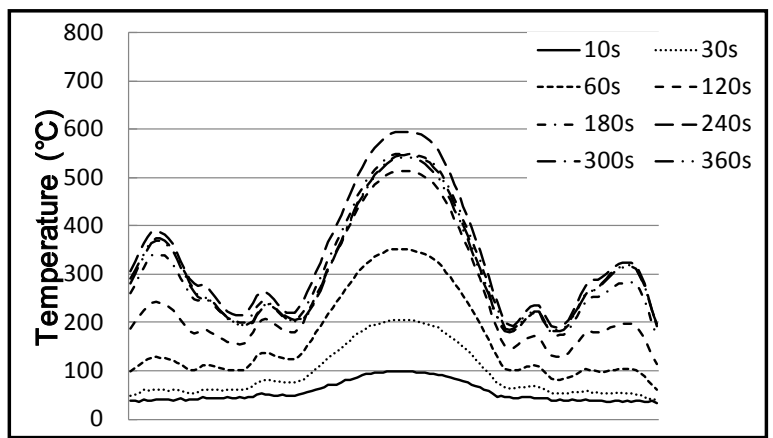

(b)

Figure 7. Temperature distribution of steel reinforcement depending on high frequency induction heating (5 kW-150 mm). (a) $5 \mathrm{~kW}$-D19-10 mm; (b) $5 \mathrm{~kW}-\mathrm{D} 25-10 \mathrm{~mm}$.

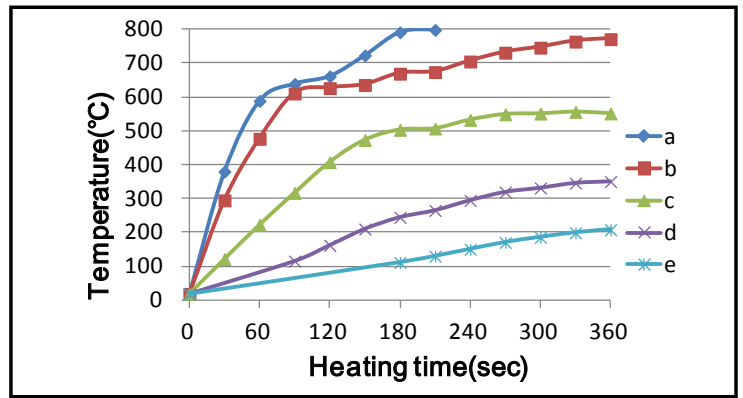

(a)

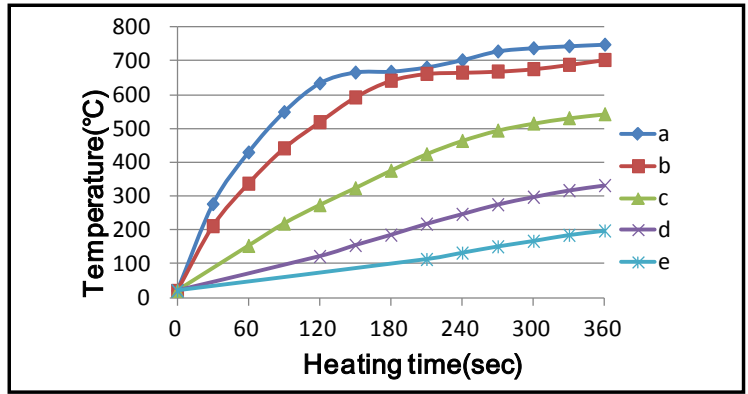

(b)

Figure 8. Temperature distribution of steel reinforcement depending on high frequency induction heating $(5 \mathrm{~kW}-450 \mathrm{~mm})$. (a) $5 \mathrm{~kW}$-D19-10 mm; (b) $5 \mathrm{~kW}$-D25-10 mm. Note: a: center of steel reinforcement, b, c, d, e: toward the end from the center of steel reinforcement 30, 60, 90, $120 \mathrm{~mm}$.

SD345. To perform the experiment in the same conditions as those of the reinforced concrete members, this study cuts the length to $355 \mathrm{~mm}$ before use. This study assumes the steel reinforcement of D19, D25, and D32 as major steel reinforcements and carries out an experiment by cross-arranging the D10 steel reinforcement at the bottom.

As shown in Figure 9, this study places three steel reinforcements at intervals of $60 \mathrm{~mm}$ from surface to surface before heating. To select the optimal heating coil position, this study attempts a method to distribute the heating coil at the cross point of steel reinforcement (center heating) and also a method to distribute the heating coil between major steel reinforcements (side heating); the temperature characteristics depending on type and distance of steel reinforcement are then evaluated. The temperature is measured at five positions at a distance of $30 \mathrm{~mm}$ from the center of the upper and lower steel reinforcement using a heat-resistant camera, similar to the single steel reinforcement heating experiment.

\subsection{Temperature Rise Characteristics of Cross-Steel Reinforcement Depending on High-Frequency Induction Heating}

With a high-frequency output of $5 \mathrm{~kW}$, the initial temperature rise curve showed the same tendency as that of the single steel reinforcement, with a sharp slope. However, it reached thermal equilibrium rapidly, showing the temperature reduction of up to $100^{\circ} \mathrm{C}$ compared to the single steel reinforcement. If the distance to the heating source was closer, there was no large temperature difference in the upper steel reinforcement of D10, but the upper and lower steel reinforcement showed a temperature difference between $80^{\circ} \mathrm{C}$ and $180^{\circ} \mathrm{C}$ when the heating distance was $40 \mathrm{~mm}$ or above. At the shortest distance, there occurs a heating phenomenon wherein a magnetic field is formed that reaches the lower steel reinforcement; at larger distances, a magnetic field is formed around the upper steel reinforcement before it reaches the lower steel reinforcement and the lower steel reinforcement is heated by conduction (as shown in Figure 10). 

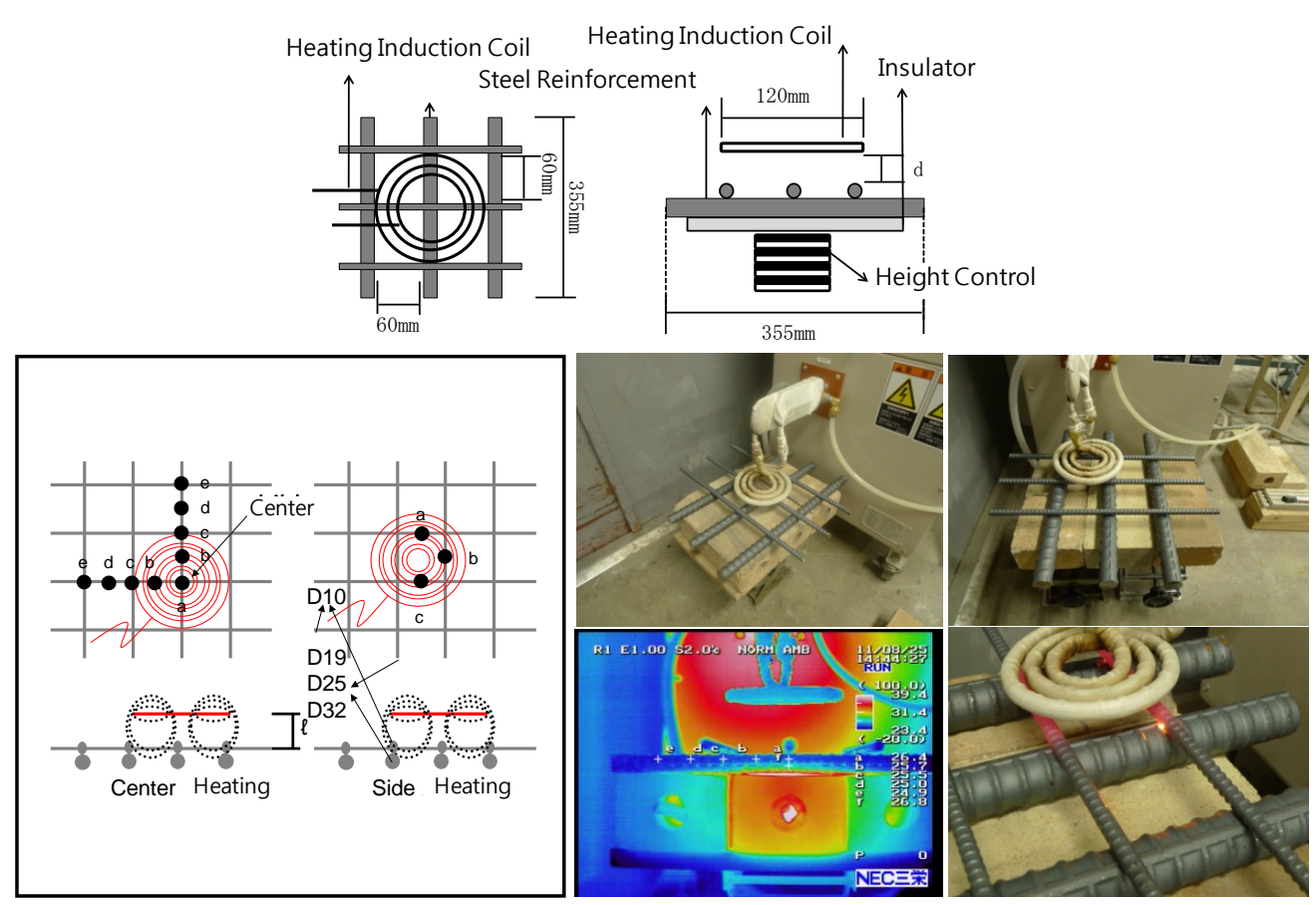

Figure 9. Experimental method of heating the cross-steel reinforcement using high-frequency induction heating.

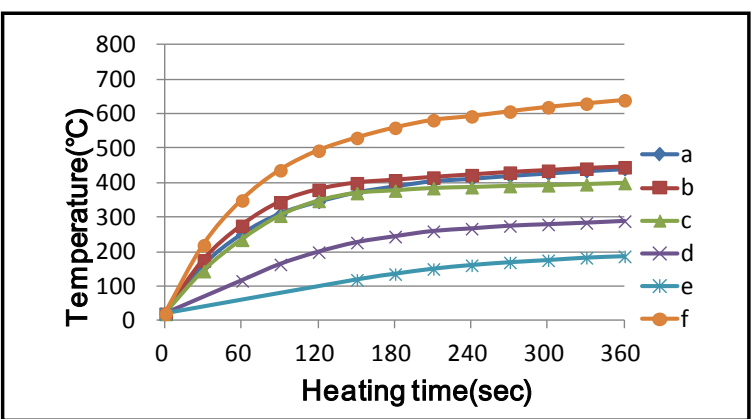

(a)

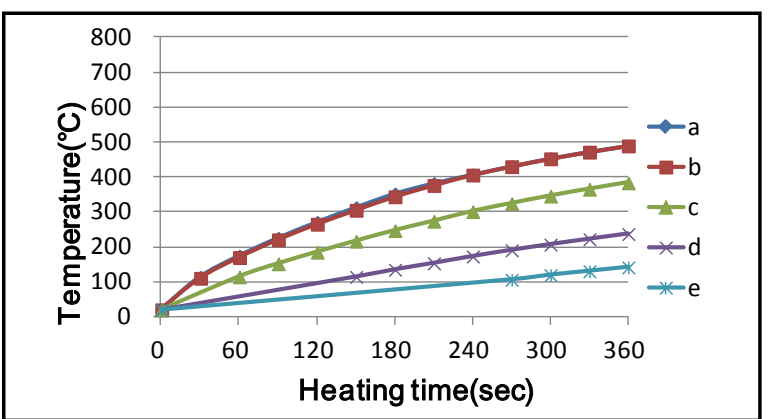

(b)

"Note: a: D00-0-0: D reinforced type-type of lower steel reinforcement-heating distance (mm).

Figure 10. Temperature rise characteristics of steel reinforcement depending on high-frequency induction heating (Center). (a) Measurement of D25-10-30 mm from the upper side; (b) Measurement of D25-10-30 mm from the lower side.

The temperature distribution shows almost the same tendency as the single steel reinforcement, but if the diameter of the heating coil is $120 \mathrm{~mm}$, the temperature differential between steel reinforcement inside the diameter and steel reinforcement outside the diameter shows a large temperature differential in the upper steel reinforcement when the heating range is between $50^{\circ} \mathrm{C}$ and $200^{\circ} \mathrm{C}$. This result can help identify the possibility of selective heating depending on the area of the magnetic field (as shown in Figure 11).

When the heating coil was placed between major steel reinforcements, the temperature rise characteristics showed a maximum difference of $100^{\circ} \mathrm{C}$. When the heating coil was placed at the point of intersection and heated, each one of the upper and lower steel reinforcements located at the center of the coil diameter showed the same heating tendency. When the heating coil was placed between the major steel reinforcements, the heating efficiency decreased slightly, but the area of heating expanded when two upper steel reinforcements and two lower steel reinforcements in the range of the magnetic field were heated at the same time, which led to an increase in the width of the heating range. This seems to be attributable to the impact of coupling efficiency on the steel reinforcement and heating coil. As shown in Equation (8) and Equation (9), the heating coil is basically a 
resistor (inductance) and thus produces heat depending on [material-length-diameter (area of surface) with the current that flows in the coil * coil resistance]. In addition, the intensity of the magnetic force is inversely proportional to 2 - 3 square of distance and proportional to the current that occurs in the coil and coil differential (relative changes in two coils). Therefore, if the coupling efficiency of steel reinforcement and coil is bad, a high current is required. There are condensers and transformers within the conditioning unit (circuit), and they become a resistance [18] [19].

$$
F=G \frac{m_{1} m_{2}}{r^{2}}
$$

$$
\begin{aligned}
& G=6.672 \times 10^{-11} \mathrm{~m}^{3} / \mathrm{kg} \cdot \mathrm{s}^{2} ; \\
& m=\text { mass; } \\
& r=\text { distance; } \\
& F=\text { output. }
\end{aligned}
$$

$$
\text { output }(\text { intensity of magnetic field })=A(\text { current }) \times T(\text { coil differential })
$$

In other words, as in Figure 12, which shows the coupling of steel reinforcement and coil, in (b), where the distance from the heating coil is the same as the distance between the coils to the surface of the steel reinforcement, two steel reinforcements are included within similar magnetic fields and thus resistance heat occurs up to a temperature like (c). Therefore, if the voltage is the same, loss within the circuit increases and the temperature of the heated object decreases with increasing current (or raised voltage).

\section{Deconstruction Assessment of Reinforced Concrete Using Hitting Method}

\subsection{Experimental Overview}

The purpose of this experiment is to evaluate the dynamic dismantlement of reinforced concrete members weakened by high-frequency induction heating. As there are no previous studies on the methods for evaluating the dismantlement of concrete members quantitatively, in most cases, qualitative evaluations such as "difficult to dismantle" are defined without evaluating the time or energy required for dismantling. Therefore, the data is not reliable as reproductive data in reviewing the expenses for dismantling or environmental load [20].

This study measures the time and energy required for unit dismantlement and makes a quantitative evaluation of dynamic dismantlement of reinforced concrete members weakened by high-frequency induction heating.

\subsection{Experimental Method}

The reinforced concrete members weakened by high-frequency induction heating were separated to the extent that steel reinforcement cutting can be done in the field. By installing 3-axis acceleration sensors in the hammer, the dismantling tool, this study measures the dismantling location and the time consumed by each experimental group. To calculate the time and energy taken for dismantling for single reinforced concrete specimens, the acceleration and direction of dismantling were measured until the steel reinforcement could be exposed by hitting a heated specimen that was heated in the longitudinal direction continuously. To calculate the time and energy taken for dismantling in the case of cross-steel reinforcement, the acceleration and direction of dismantling were measured until the steel reinforcement could be exposed by hitting a heated specimen that was heated by induction heating of both the center and side.

\subsection{Deconstruction Assessment of Single Reinforced Concrete}

The separating experiment results that compare the specimen with $30 \mathrm{~mm}$ steel reinforcement covering depth (D19), which requires the least electricity for the separation, before and after heating, are represented in Figure 13 and Figure 14.

In most of the specimens, the destruction power showed a reducing tendency with increasing diameter of steel reinforcement, and the power required for destruction decreased with decreasing distance from the induction heating coil. In case of the specimen using D10, with the least heating efficiency, the power depending on the induction heating was the smallest. However, it showed a tendency that it reduced more greatly at $30 \mathrm{~mm}-\mathrm{a}$ smaller heating distance - than at $40 \mathrm{~mm}$ or $50 \mathrm{~mm}$. When the heating distance was smaller, the temperature of 


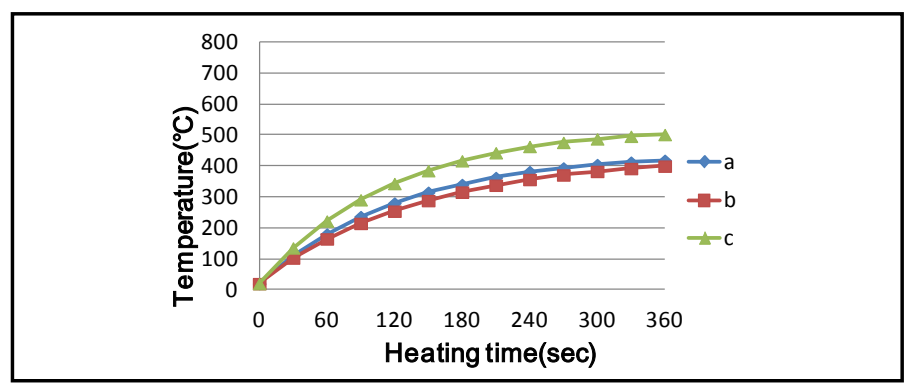

Figure 11. Temperature rise characteristics of steel reinforcement depending on high-frequency induction heating (Side).

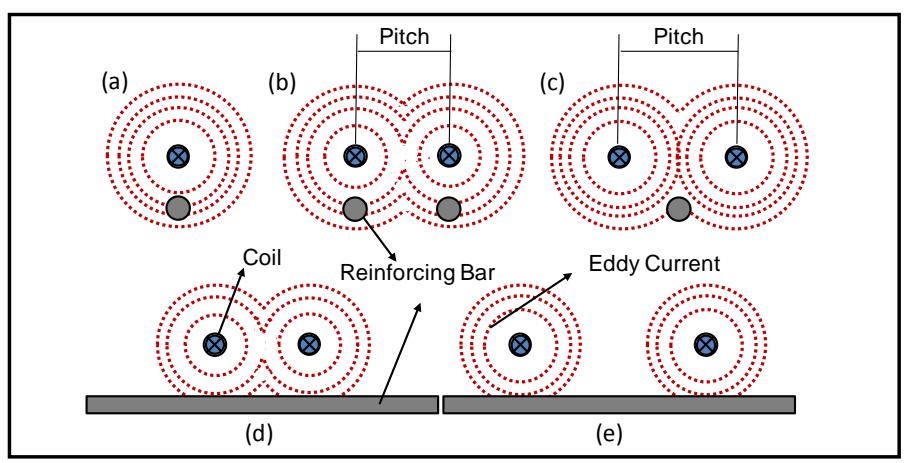

Figure 12. Improved coupling efficiency in steel reinforcement and heating coil.

steel reinforcement rose rapidly; when the diameter of steel reinforcement was small, thermal equilibrium was reached immediately after heating and the heat conduction velocity for concrete increased and then weakened immediately. This is why the breaking stress was smaller than it was for other specimens with relatively thicker covering depths.

In case of D19 and D25, with higher heating efficiency, a reduction in destruction stress with heating distance was evident. In the case of D19, the reducing rate at covering depths of $50 \mathrm{~mm}$ and $30 \mathrm{~mm}$ had about a $69 \%$ difference; for D25, there was about a 71\% difference. For D32, with the smallest destruction stress, there was about an $83 \%$ reducing rate compared to the standard specimen. There may be some errors in the destruction stress caused by the increased covering thickness, but D19 showed about a 77\% reducing rate, compared to the standard specimen.

\subsection{Deconstruction Assessment of Cross-Reinforced Concrete}

The specimen that was heated at the center showed a decreased tendency for destruction stress compared to the specimen that was heated at the side. With a covering thickness of $30 \mathrm{~mm}$, the center-heated sample showed about a 39\% reducing rate and the side-heated sample showed about a $31 \%$ reducing rate, which suggested that there was an $8 \%$ difference. Compared to the center heating, crack propagation showed a high efficiency when heating the side, but the center heating showed a high heating efficiency in the crack width and internal temperature rise ratio. Therefore, center heating may be influential on the stress required to separate steel reinforcement from concrete (as shown in Figure 15 and Figure 16).

The overall tendency before and after high-frequency induction heating increased according to the covering thickness. The crack width caused by the expansion pressure depending on heating is more influential to the steel reinforcement than is chemical weakening, which depends on thermal conduction.

\section{Conclusions}

This study carries out an experiment to separate steel reinforcement from concrete as completely as possible through indirect heating using high-frequency induction heating, especially of the steel reinforcement inside the 


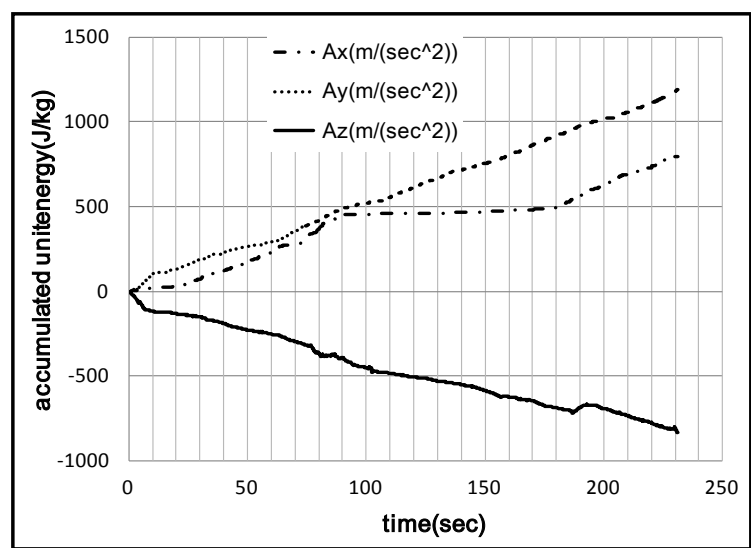

(a)

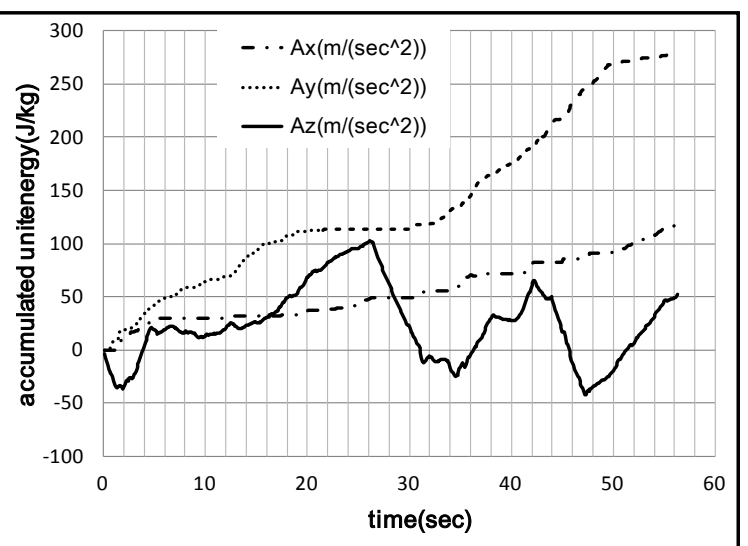

(b)

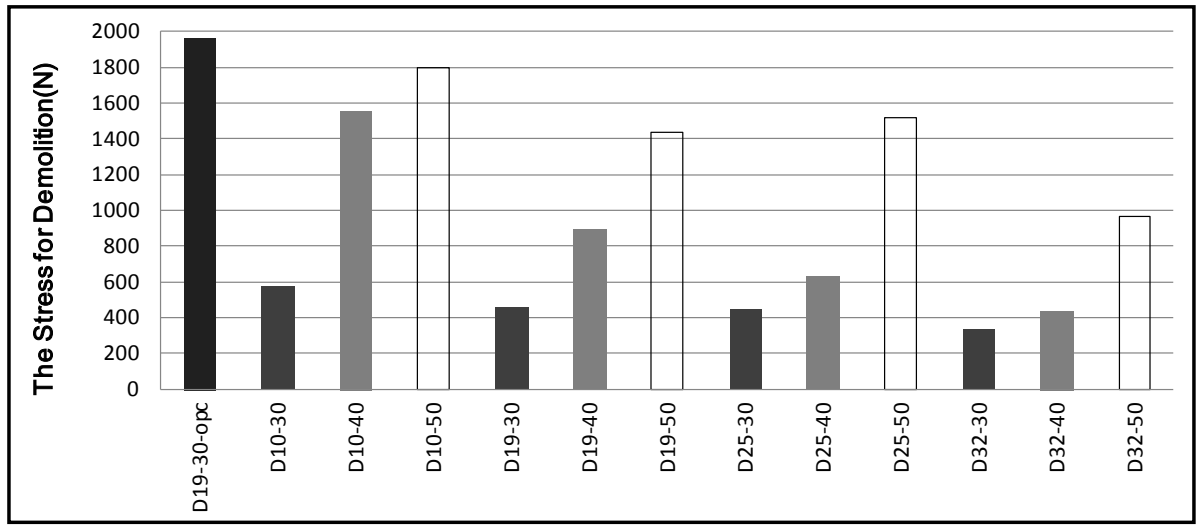

(c)

Figure 13. Experiment result of deconstruction of single reinforced concrete member after high frequency induction heating. (a) Specimen before heating (D19 - 30 mm); (b) Specimen after heating (D19 - $30 \mathrm{~mm}$ ); (c) Resolved stress of reinforced concrete member.
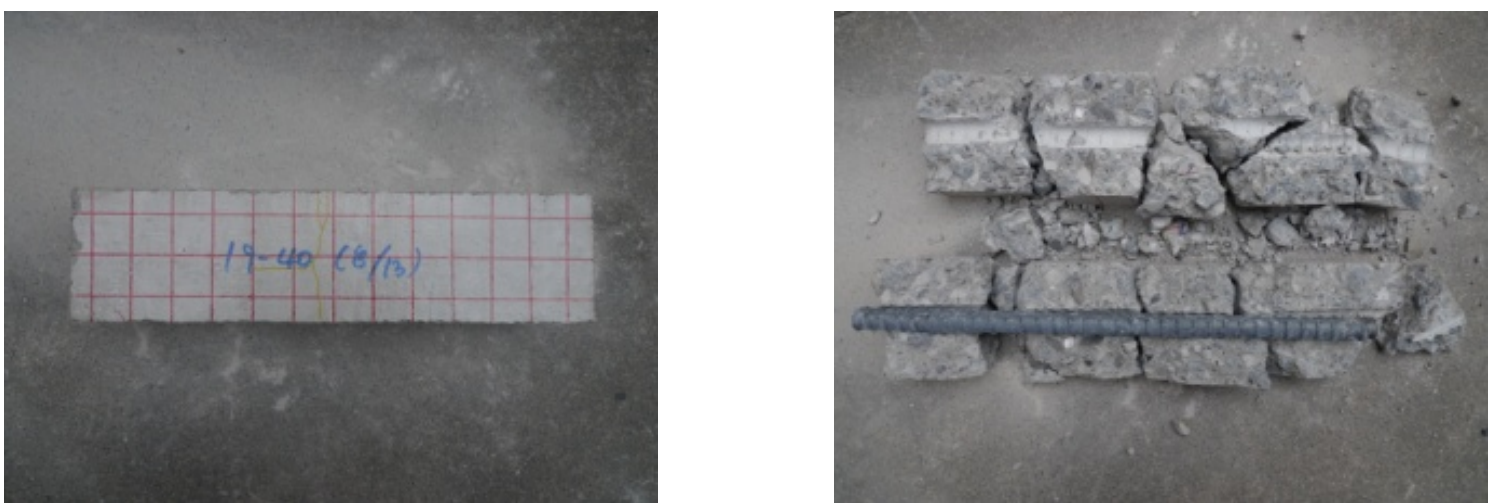

Figure 14. Experiment result of complete deconstruction of single reinforced concrete member after heating.

reinforced concrete, and the findings are as follows:

1) The frequency with the maximum output determines the depth of penetration in the induction heating. If the output increases enough to heat the steel reinforcement that is far from the heating coil, current density and intensity of magnetic field increase in general, but the depth of penetration decreases. Thus, it is necessary to take into account the appropriate output at a certain distance. As the appropriate output does not show any large difference in temperature rise with time at a distance of less than $40 \mathrm{~mm}$, the output of $5 \mathrm{~kW}$ or above leads to heat loss at temperatures higher than the Curie point and there is a problem in power dissipation. 


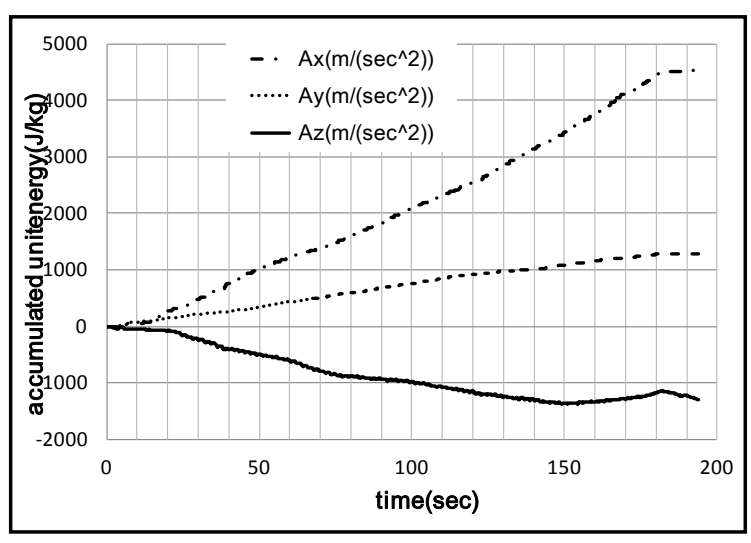

(a)

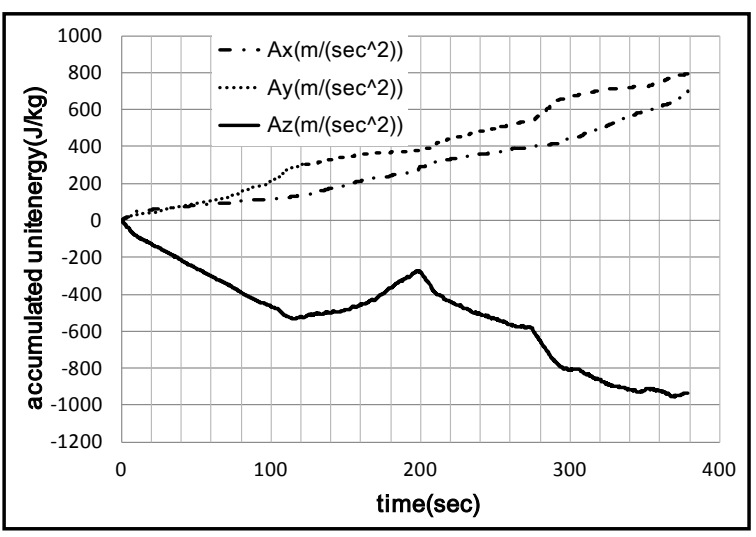

(b)

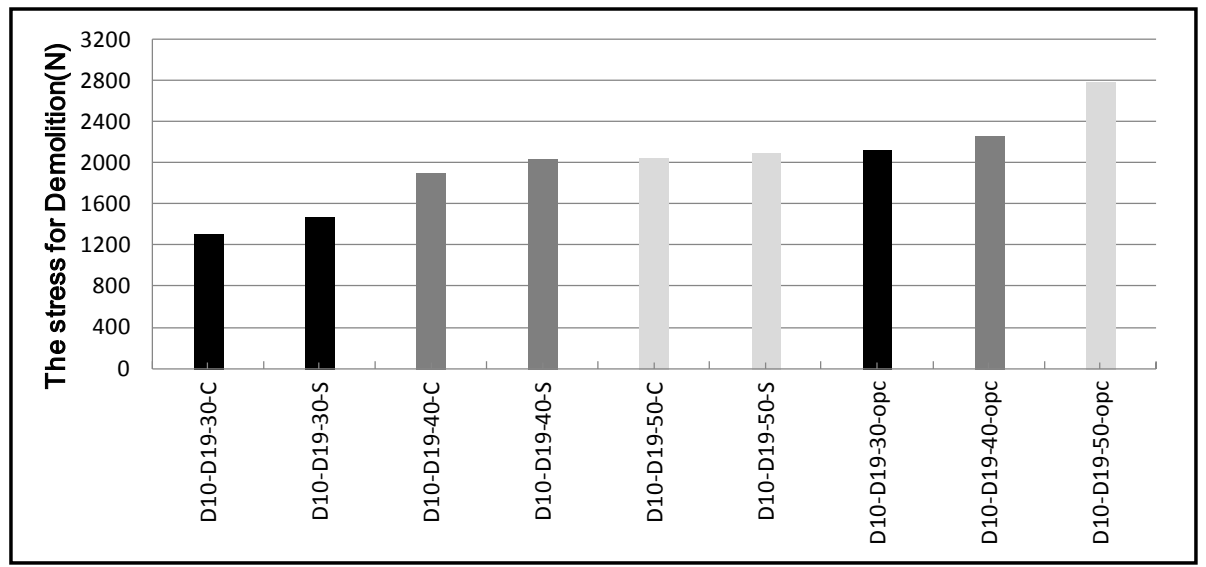

(c)

Figure 15. Experiment result of destructing the cross-reinforced concrete member after high frequency induction heating. (a) Specimen before heating (D19-10-30 mm) the center; (b) Specimen after heating (D19-10-30 mm) the center; (c) Resolved stress of reinforced concrete member.
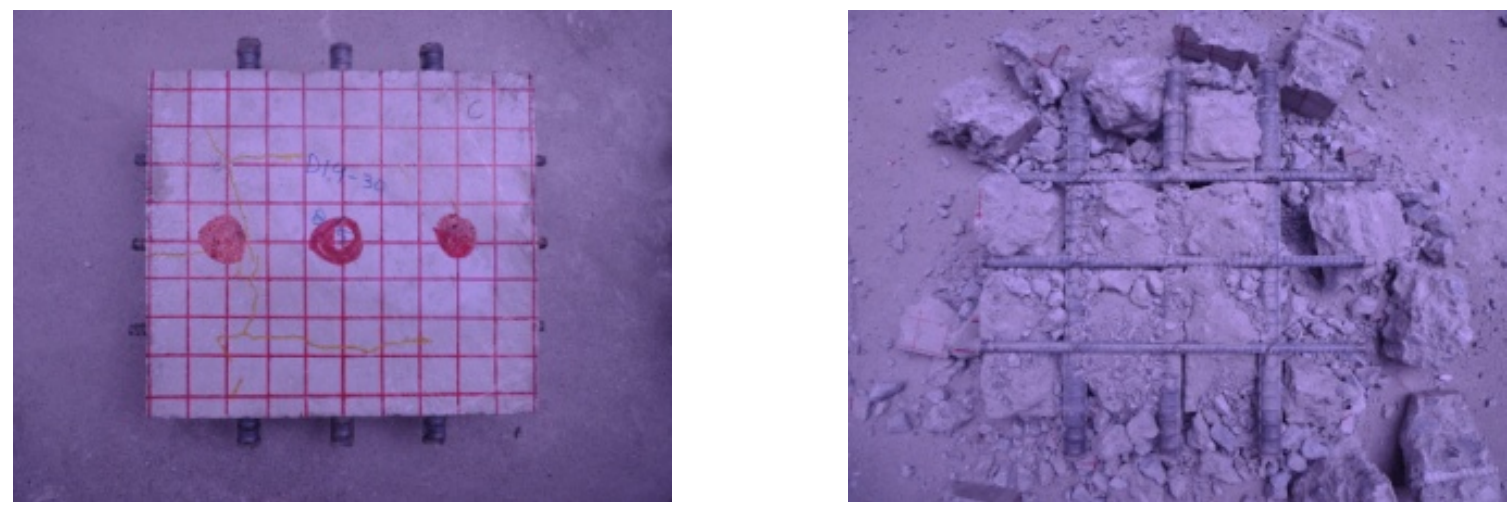

Figure 16. Experiment result of destructing the cross-reinforced concrete member after heating.

2) Using the high-frequency induction heating method, the surface of steel reinforcement can be heated up to $300^{\circ} \mathrm{C}$, at which the concrete-weakening temperature is the most effective. As the heating range is closely related to the diameter of the heating coil, selective heating up to $30 \mathrm{~mm}$ in the horizontal direction is possible based on the heating coil. With cross-arranged steel reinforcement, a covering thickness of $40 \mathrm{~mm}$ is possible for an effective heating, and a covering thickness of $50 \mathrm{~mm}$ or above is possible for an effective heating by thermal conduction through the upper steel reinforcement. 
3) When high-frequency induction heating is applied to the structure in the field, steel reinforcement can be cut by exposing the steel reinforcement using the hitting method after weakening the concrete by the occurrence of cracks caused by the heated expansion pressure and thermal conduction. Thus, effective work is possible owing to weakening caused by rapid heating of the exposed steel reinforcement.

The high-frequency induction heating technology proposed in this study may be applicable to the field of dismantling existing high-rise buildings, fields where workers cannot use heavy equipment, and fields that are sensitive to pollutants such as noise and dust. Particularly in the field of dismantling single structures with localized dismantling, for example, repair or reinforcement, highly efficient dismantling is expected to be possible.

\section{Acknowledgements}

This work was supported by the GRRC program of Gyeonggi province. [(GRRC HANKYONG 2011-B05), Carbon Neutral Wall and Floor Elements for Smart Distribution Center].

\section{References}

[1] World Economic Forum (2014) The Global Energy Architecture Performance Index Report 2014. Cologny.

[2] Robert, W. and Messler, J.R. (2004) Joining of Materials and Structures: From Pragmatic Process to Enabling Technology. Elsevier Inc., Amsterdam.

[3] Gatta, D. (2003) Generation and Management of Construction and Demolition Waste in Greece-An Existing Challenge. Resources, Conservation and Recycling, 40, 81-91. http://dx.doi.org/10.1016/S0921-3449(03)00035-1

[4] Mizutani, R. and Yoshikai, S. (2011) A New Demolition Method for Tall Building. Kajima Cut \& Take down Method. CTBUH Journal, 5.

[5] Sealey, B.J., Phillips, P.S. and Hill, G.J. (2011) Waste Management Issues for the UK Ready-Mixed Concrete Industry. Resources. Conservation and Recycling, 32, 321-324. http://dx.doi.org/10.1016/S0921-3449(01)00069-6

[6] Uttam, K. and Balfors, B. (2014) 9-Green Public Procurement (GPP) of Construction and Building Materials. EcoEfficient Construction and Building Materials, Life Cycle Assessment (LCA), Eco-Labelling and Case Studies, 166195. http://dx.doi.org/10.1533/9780857097729.1.166

[7] Sthiannopkao, S. and Wong, M.H. (2013) Handling E-Waste in Developed and Developing Countries: Initiatives, Practices, and Consequences. Science of The Total Environment, 463-464, 1147-1153.

http://dx.doi.org/10.1016/j.scitotenv.2012.06.088

[8] Lin, F. (2012) The Development Path of Japanese Green Architecture under Energy Policy —Taking Misawa Home as an Example. Energy Procedia, 14, 1305-1310. http://dx.doi.org/10.1016/j.egypro.2011.12.1093

[9] Li, C.E., Burke, N., Gerdes, K. and Patel, J. (2013) The Undiluted, Non-Catalytic Partial Oxidation of Methane in a Flow Tube Reactor-An Experimental Study Using Indirect Induction Heating. Fuel, 109, 409-416. http://dx.doi.org/10.1016/j.fuel.2013.02.055

[10] Panão, M.R.O., Correia, A.M. and Moreira, A.L.N. (2012) High-Power Electronics Thermal Management with Intermittent Multijet Sprays. Applied Thermal Engineering, 37, 293-301. http://dx.doi.org/10.1016/j.applthermaleng.2011.11.031

[11] Wrzuszczak, M. and Wrzuszczak, J. (2005) Eddy Current Flaw Detection with Neural Network Applications. Measurement, 38, 132-136. http://dx.doi.org/10.1016/j.measurement.2005.04.004

[12] Myrhaug, D. and Holmedal, L.E. (2014) Wave-Induced Current for Long-Crested and Short-Crested Random Waves. Ocean Engineering, 81, 105-110. http://dx.doi.org/10.1016/j.oceaneng.2014.02.017

[13] Xiao, C.-L. and Huang, H.-X. (2014) Optimal Design of Heating System for Rapid Thermal Cycling Mold Using Particle Swarm Optimization and Finite Element Method. Applied Thermal Engineering, 64, 462-470. http://dx.doi.org/10.1016/j.applthermaleng.2013.12.062

[14] Postacchini, M. and Brocchini, M. (2014) A Wave-by-Wave Analysis for the Evaluation of the Breaking-Wave Celerity. Applied Ocean Research, 46, 15-27. http://dx.doi.org/10.1016/j.apor.2014.01.005

[15] http://www.ndt-ed.org/EducationResources/CommunityCollege/MagParticle/Physics/HysteresisLoop.htm

[16] Hukushima, Y. (2009) Experimental High Frequency Induction Heating Collision Instruction Manual (IMC-ADH-502). Imecs Corporation, Japan.

[17] Sadeghipour, K., Dopkin, J.A. and Li, K. (1996) A Computer-Aided Finite Element/Experimental Analysis of Induction Heating Process of Steel. Computers in Industry, 28, 195-205. http://dx.doi.org/10.1016/0166-3615(95)00072-0

[18] Lee, K.S. and Hwang, B. (2014) An Approach to Triangular Induction Heating in Final Precision Forming of Thick 
Steel Plates. Journal of Materials Processing Technology, 214, 1008-1017. http://dx.doi.org/10.1016/j.jmatprotec.2013.11.002

[19] Kima, W., Suha, C.-Y., Roha, K.-M. and Choa, S.-W. (2013) Mechanical Properties of (W, Ti)C and (W, Ti)C-NiAl3 Cermet Consolidated by the High-Frequency Induction-Heating Method. Journal of Alloys and Compounds, 568, 7377. http://dx.doi.org/10.1016/j.jallcom.2013.02.187

[20] Cho, K.-H. (2012) Coupled Electro-Magneto-Thermal Model for Induction Heating Process of a Moving Billet. International Journal of Thermal Sciences, 60, 195-204. http://dx.doi.org/10.1016/j.ijthermalsci.2012.05.003 